\title{
Cambio de dirección, pero no de rumbo
}

$\mathbf{E}$

ste es mi último número como editor en jefe de Prometeica, desde el próximo me reemplazará en esta función: Emiliano Aldegani. Desde 2010, cuando junto a Thaís Forato fundamos Prometeica, pasaron catorce números con muchos aportes de distintos especialistas, tanto en forma de artículos, reseñas, entrevistas, ensayos como en forma de tareas de evaluación o diseño. Gracias a todos ustedes.

Desde el primer número quisimos que Prometeica fuera un espacio crítico y divulgativo que permitiera un diálogo entre disciplinas que fuera desde la filosofía a la didáctica de las ciencias. Nos interesaba recuperar el término "ciencia" en su sentido más amplio, procurando mantener la calidad académica de las contribuciones, estimular el debate y buscar el progreso continuo para la publicación. Sé que mi tarea como director tuvo flaquezas y que muchos de esos objetivos aún necesitan seguir desarrollándose. Sin embargo, tengo la profunda confianza de que Emiliano podrá continuar con la misión fundacional de Prometeica y que con su energía y empeño subsanará las falencias que hoy le lego.

Asimismo, aprovecho para contarles que cuando elegí el nombre Prometeica, no lo hice sólo por nostalgia de mi primera revista PrometheusMDQ, sino que esperaba que la publicación fuera una empresa "prometeica" en su sentido más amplio, es decir, que impulsara el conocimiento de un modo gratuito, libre y humanitario. Hoy más que nunca el nombre tiene ese sentido para mí.

Gracias a todos por estos seis años de intercambiar ideas, en especial a Thaís, Ivy, Flaminio, Emiliano quienes seguirán en el arduo trabajo editorial y quienes recibirán vuestras contribuciones a través de la plataforma OJS o al mail info@prometeica.com. Me enorgullece despedirme con un número como este, que no sólo estrena una nueva sección a cargo de Thaís (Educación en ciencias: pluralidades epistemológicas) sino que fiel a mi espíritu internacionalista cuenta con contribuciones de autores de Argentina, Brasil, Colombia, Eslovaquia y España.

Nuevamente, queridos lectores y autores, muchas gracias por confiar en Prometeica.

Lucas E. Misseri 